Check for updates

Cite this: RSC Adv., 2019, 9, 28357

Received 2nd July 2019

Accepted 3rd September 2019

DOI: 10.1039/c9ra04995a

rsc.li/rsc-advances

\title{
Synthesis, photophysical and electrochemical properties of a new star-shaped molecule with a 1,3,5-triethynylbenzene core and diketopyrrolopyrrole arms $\dagger$
}

\begin{abstract}
Chunpeng Li, Qingfen Niu, (D) * Shanshan Zhang, Tianduo Li and Qingxin Yang
A new star-shaped small molecule BDPP-1 based on 1,3,5-triethynylbenzene as a core and diketopyrrolopyrrole (DPP) as rigid arms have been successfully designed and synthesized. The thermal stability, photophysical and electrochemical properties were explored. The synthesized star-shaped small molecule BDPP-1 exhibited excellent solubility, high thermal stability, broad and strong absorption, narrow band gap and appropriate molecular levels. Moreover, the photoinduced charge separation process between the synthesized donor and acceptor $\mathrm{PC}_{61} \mathrm{BM}$ was evaluated by the fluorescence quenching experiment, revealing that the donor material BDPP-1 possessed efficient photoinduced charge separation performance. These detailed investigations on the structure-property relationship of the novel star-shaped molecule revealed that BDPP-1 is a prospective candidate as a donor material for organic photovoltaic materials.
\end{abstract}

\section{Introduction}

Recently, various design rules and interesting new materials have been explored including organic small molecules (OSMs) and polymers. Among many functional materials, the small conjugated organic molecule based materials have gained much attention because of their unique advantages of welldefined molecular structure, definite molecular weight, high purity, and better batch-to-batch reproducibility. ${ }^{1-3}$ Such conjugated small molecules generally included linear molecules, ${ }^{4,5}$ star-shaped molecules, ${ }^{6,7}$ X-shaped molecules, ${ }^{8}$ and dendritic molecules. ${ }^{9}$ As is well known, the star-shaped small molecules of $\pi$-conjugated structure have displayed many outstanding advantages over linear conjugated small molecules such as monodispersity, excellent solubility as well as vast structures with different functional groups. Moreover, the enlarged $\pi$-conjugated structure can bring forth a strong propensity for stacking into 1D columns as the preferred charge transporting pathway, which supports to improve the carrier mobilities of the functional materials. ${ }^{9-11}$ More recently, the star-shaped small molecules have also attracted considerable attention as donor/acceptor materials in solution-processed bulk heterojunction (BHJ) organic solar cells (OSCs) in terms

Shandong Provincial Key Laboratory of Molecular Engineering, School of Chemistry and Pharmaceutical Engineering, Qilu University of Technology (Shandong Academy of Sciences), Jinan 250353, People's Republic of China. E-mail: qf_niu1216@qlu. edu.cn

$\dagger$ Electronic supplementary information (ESI) available. See DOI: 10.1039/c9ra04995a of their intriguing properties such as high solution processability, high thermal stability, good absorption coefficient, high mobility, narrow band gap as well as strong and broad absorption in the visible region. ${ }^{12-15}$ So far, the reported starshaped molecules are frequently developed through tanglesome synthetic methodologies from several well-known cores such as phenylene $\mathrm{e}^{16-18}$ triphenylamine ${ }^{19-21}$ and truxene. ${ }^{22,23}$ Therefore, more efforts should be focused on the seeking of new cores and straightforward synthetic methodologies to develop advanced star-shaped molecular materials for the time being.

Diketopyrrolopyrrole (DPP) as a promising acceptor unit has received a great deal of attention for optoelectronic applications due to its easy and large-scale preparation, unique $\pi$-conjugated system, excellent coplanarity, strong and broad absorption, high fluorescence quantum, exceptional stability and modification of $N$-alkyl chains. ${ }^{24-28}$ For the time being, DPP based compounds have got huge fame attributed to their excellent photophysical properties such as high molar extinction coefficient, high thermal and photo stability. Because of their structural versatility, they have been used as p-type, n-type, or ambipolar organic semiconductors in organic electronics including organic photovoltaic cells (OPVs) ${ }^{29}$ field effect transistors $^{30-32}$ and chemo/bio-sensors. ${ }^{33}$

Currently, many C3-symmetric functionalized groups have been used to build star-shaped molecules, ${ }^{34,35}$ which have attracted considerable attention in the field of materials science owing to their divergent and extended $\pi$-conjugation. The classes of C3-symmetric star-shaped molecules are also found to have important applications in liquid crystals, photovoltaics, 
organic field-effect transistors, organic light-emitting diodes, electroluminescent devices as well as organic solar cells. ${ }^{36-38}$ Some C3-symmetric molecules containing heterocycles have been synthesized and utilized in electro-optical materials, and separation science. ${ }^{39}$ As part of our program aimed at designing new star-shaped C3-symmetric molecules, we conceived new strategy to DPP-based C3-symmetric molecules, and the incorporation of arylene ethynylene structural motifs into $\pi$-conjugated compounds is expected to render them more interesting and desirable properties and hence is of great interest to us.

In this study, we report on the synthesis and comprehensive study of a new star-shaped small molecules based on 1,3,5triethynylbenzene as core and $N$-alkyl substituted DPP as rigid arms. The structure of $6,6^{\prime}, 6^{\prime \prime}-\left(5,5^{\prime}, 5^{\prime \prime}\right.$-(benzene-1,3,5-triyltris(ethyne-2,1-diyl))-tris(thiophene-5,2-diyl))tris(2,5-dioctyl-3(thiophen-2-yl)pyrrolo[3,4-c]pyrrole-1,4(2H,5H)-dione) (BDPP-1) is shown in Fig. 1. The whole molecule based on a 1,3,5-triethynylbenzene core is symmetric with a three-branched structure. Its thermal, optical, electrochemical and electronic properties have been well investigated. The investigated results indicate that the synthesized star-shaped small molecule BDPP$\mathbf{1}$ has a great potential as a donor material for organic photovoltaic applications.

\section{Experimental}

\section{Materials}

All reagents were obtained commercially and used without further purification, unless otherwise noted. Toluene and tetrahydrofuran were dried by distillation from metallic sodium/benzophenone under nitrogen atmosphere before use. Unless otherwise stated, all reaction carried in an air atmosphere. Compounds 1,3,5-triethynylbenzene, ${ }^{\mathbf{4 0}}$ and DPP-1 ${ }^{\mathbf{4 1}}$ were synthesized following the same procedure as reported in the literature.

\section{Measurements and characterizations}

${ }^{1} \mathrm{H}$ and ${ }^{13} \mathrm{C}$ NMR spectra were collected on a Bruker Avance II $400 \mathrm{MHz}$ spectrometer with $\mathrm{CDCl}_{3}$ as the solvent with tetramethylsilane (TMS) as an internal reference. Infrared measurements with the $\mathrm{KBr}$ pellet technique were performed within the $4000-400 \mathrm{~cm}^{-1}$ region on a Bruker ALPHA FT-IR

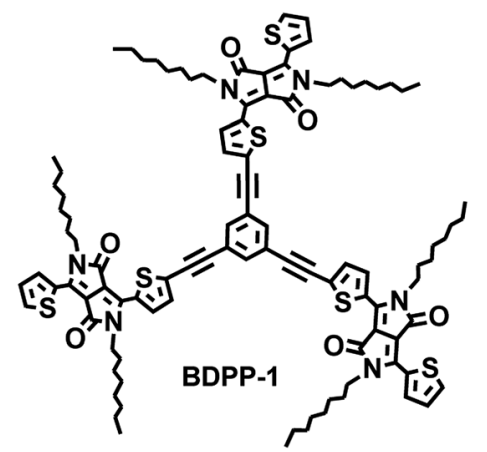

Fig. 1 The chemical structure of BDPP-1. spectrometer. Mass spectra were measured on Agilent 1100 MS series/AXIMA CFR MALDI/TOF (matrix assisted laser desorption ionization/time-of-flight) MS (COMPACT). Elemental analysis for carbon, hydrogen, nitrogen and sulfur was performed using an Elementar Vario EL III elemental analyzer. UV-vis spectra of these samples (in $\mathrm{CHCl}_{3}$ solution or solid state) were recorded using a Hitachi U-4100 spectrometer. All fluorescence measurements were carried out on a Hitachi F4600 fluorescence spectrophotometer with a scan rate at 2400 $\mathrm{nm} \min ^{-1}$ at room temperature. For fluorescence measurements, the slits for excitation and emission were set at $5 / 5 \mathrm{~nm}$, respectively. The excitation wavelength was set at $560 \mathrm{~nm}$. Thermogravimetric analysis (TGA) measurements were obtained by TA Q500 instrument with heating rate of $10^{\circ} \mathrm{C} \mathrm{min}^{-1}$ under nitrogen condition from room temperature to $800{ }^{\circ} \mathrm{C}$ at ambient pressure. All CV measurements were carried out at room temperature on a CHI832 electrochemical instrument with a three-electrode cell in a solution of $0.1 \mathrm{M}$ tetrabutylammonium perchlorate $\left(\mathrm{Bu}_{4} \mathrm{NClO}_{4}\right)$ in anhydrous dichloromethane at room temperature under nitrogen atmosphere with a scan rate of $50 \mathrm{mV} \mathrm{s}^{-1}$. The working electrode was platinum electrode, the counter electrode was a platinized platinum wire of large area, and the reference electrode was $\mathrm{Ag} / \mathrm{AgCl}(\mathrm{Ag}$ in $0.1 \mathrm{M} \mathrm{AgNO}_{3}$ solution of MeCN) which was separated by a diaphragm. Ferrocene-ferrocenium $\left(\mathrm{Fc} / \mathrm{Fc}^{+}\right)$couple was chosen as internal standard. Thin-layer chromatography (TLC) was carried out with silica gel GF254 covered on plastic sheets and visualized by UV lamp, and flash column chromatographic separation was performed over silica gel.

Synthesis of $6,6^{\prime}, 6^{\prime \prime}$-(5, $5^{\prime}, 5^{\prime \prime}$-(benzene-1,3,5-triyltris(ethyne-2,1diyl))-tris(thiophene-5,2-diyl))tris(2,5-dioctyl-3-(thiophen-2-yl) pyrrolo[3,4-c]pyrrole-1,4(2H,5H)-dione) (BDPP-1)

Following the Sonogashira coupling procedure, 1,3,5-triethynylbenzene (0.15 g, $1.00 \mathrm{mmol})$ and DPP-1 (1.80 g, $3.00 \mathrm{mmol})$ were dissolved in dry triethylamine $(50 \mathrm{~mL})$ and dry toluene $(50$ $\mathrm{mL})$ under an atmosphere of nitrogen. Copper(I) iodide $(0.20 \mathrm{~g}$, $1.00 \mathrm{mmol}$ ) and dichlorobis(triphenylphosphine)palladium(II) $(0.04 \mathrm{~g}, 0.05 \mathrm{mmol})$ were added to the stirred solution. Then the mixture was heated to $110{ }^{\circ} \mathrm{C}$ for $24 \mathrm{~h}$ by stirring under nitrogen atmosphere. After cooling, the formed precipitate of triethylamine hydroiodide was filtered off and washed with diethyl ether. The combined filtrates were evaporated under reduced pressure, and the crude product was purified by silica column chromatography eluting with petroleum ether/ dichloromethane $(\mathrm{v}: \mathrm{v}=1: 2)$ to afford compound BDPP-1 $(0.46 \mathrm{~g}, 25 \%)$ as a dark purplish red solid. FT-IR $\left(\mathrm{KBr}, \mathrm{cm}^{-1}\right): v=$ 3078, 2957, 2924, 2855, 2195, 1666, 1556, 1453, 1404, 1381, 1314, 1235, 1162, 1092, 1066, 1022, 923, 857, 817, 731, 711, 671; ${ }^{1} \mathrm{H}$ NMR (400 MHz, $\left.\mathrm{CDCl}_{3}, \mathrm{ppm}\right): \delta 8.91(\mathrm{~d}, J=2.8 \mathrm{~Hz}, 3 \mathrm{H}), 8.86$ $(\mathrm{d}, J=3.6 \mathrm{~Hz}, 3 \mathrm{H}), 7.62(\mathrm{~s}, 3 \mathrm{H}), 7.58(\mathrm{~d}, J=4.0 \mathrm{~Hz}, 3 \mathrm{H}), 7.36(\mathrm{~d}, J$ $=4.0 \mathrm{~Hz}, 3 \mathrm{H}), 7.22(\mathrm{t}, J=4.0 \mathrm{~Hz}, 3 \mathrm{H}), 4.00(\mathrm{t}, J=3.2 \mathrm{~Hz}, 12 \mathrm{H})$, $1.68(\mathrm{~m}, 12 \mathrm{H}), 1.55(\mathrm{~m}, 12 \mathrm{H}), 1.36(\mathrm{~m}, 12 \mathrm{H}), 1.19(\mathrm{~m}, 36 \mathrm{H}), 0.81$ $(\mathrm{t}, J=7.6 \mathrm{~Hz}, 18 \mathrm{H}) ;{ }^{13} \mathrm{C} \mathrm{NMR}\left(100 \mathrm{MHz}, \mathrm{CDCl}_{3}, \mathrm{ppm}\right): \delta 160.69$, 160.56, 139.94, 137.97, 135.16, 134.59, 133.42, 133.15, 130.78, $130.31,129.22,128.28,126.74,123.09$, 108.28, 107.31, 94.79, 
$83.56,67.66,41.83,38.28,31.25,29.89,29.55,29.41,29.16$, 28.66, 28.42, 26.38, 23.28, 22.44, 22.09, 13.52, 10.42; MALDITOF MS: calc. for $\mathrm{C}_{102} \mathrm{H}_{120} \mathrm{~N}_{6} \mathrm{O}_{6} \mathrm{~S}_{6}$ : [M] 1716.8, found: [M] 1716.5; anal. calcd (\%) for $\mathrm{C}_{102} \mathrm{H}_{120} \mathrm{~N}_{6} \mathrm{O}_{6} \mathrm{~S}_{6}$ : C, 71.29; H, 7.04; N, 4.89; S, 11.20. Found: C, 71.21; H, 7.11; N, 4.86; S, 11.18.

\section{Results and discussion}

\section{Synthesis and thermal stability properties}

The synthetic route of BDPP-1 is outlined in Scheme 1. Starshaped molecule BDPP-1 was synthesized by Pd-assisted Sonogashira coupling reaction. The chemical structure was determined with ${ }^{1} \mathrm{H}$ NMR, ${ }^{13} \mathrm{C}$ NMR, IR and MALDI-TOF MS, which was consistent with its proposed structure. The donor material possesses good solubility in common organic solvents such as THF, diether, dichloromethane, chloroform and dichlorobenzene due to the $N$-alkyl-substituted DPP as a segment of the molecular backbone, which allows it to be easily purified by column chromatography and also meets the requirement for fabrication of solution-processed OPV device. The thermal stability of the compound BDPP-1 was explored by TGA as shown in Fig. 2. BDPP-1 has good thermal stability with onset decomposition temperature corresponding to $5 \%$ weight loss at $315{ }^{\circ} \mathrm{C}$. Obviously, the thermal stability of the material BDPP-1 was good enough for application in OPV device. ${ }^{42}$

\section{Optical properties}

The optical properties of the star-shaped molecule BDPP-1 was preliminarily studied by using UV-vis absorption measurement. The normalized UV-vis absorption spectra of the material in chloroform solution $\left(1.7170 \mathrm{mg} \mathrm{mL}^{-1}\right)$ and in thin film are depicted in Fig. 3. The compound BDPP-1 shows two primary absorption bands at low and high energy region with a broad absorption range covering 320-630 $\mathrm{nm}$ in solution and 300$750 \mathrm{~nm}$ in thin film state, respectively, with a high molar extinction coefficient $(\varepsilon)$ of $1.00 \times 10^{5} \mathrm{M}^{-1} \mathrm{~cm}^{-1}$ at $577 \mathrm{~nm}$. The absorption peak in lower wavelength region (around $360 \mathrm{~nm}$ ) is ascribed to the $\pi-\pi^{*}$ transition of the conjugated backbone, whereas the lower energy absorption band peaking at $586 \mathrm{~nm}$ can be attributed to intramolecular charge transfer (ICT) transition between donor and acceptor unit of the star-shaped OSMs. ${ }^{43}$ In solid state, the main absorption peaks became broader and showed an ICT peak around $614 \mathrm{~nm}$, which is red shifted by $28 \mathrm{~nm}$ as compared to that in solution. This may be attributed to the enhanced intermolecular $\pi-\pi$ interactions in

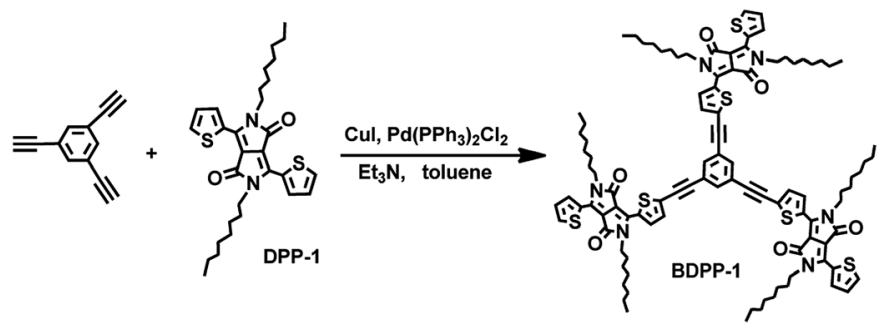

Scheme 1 Synthetic route of the star-shaped compound BDPP-1.

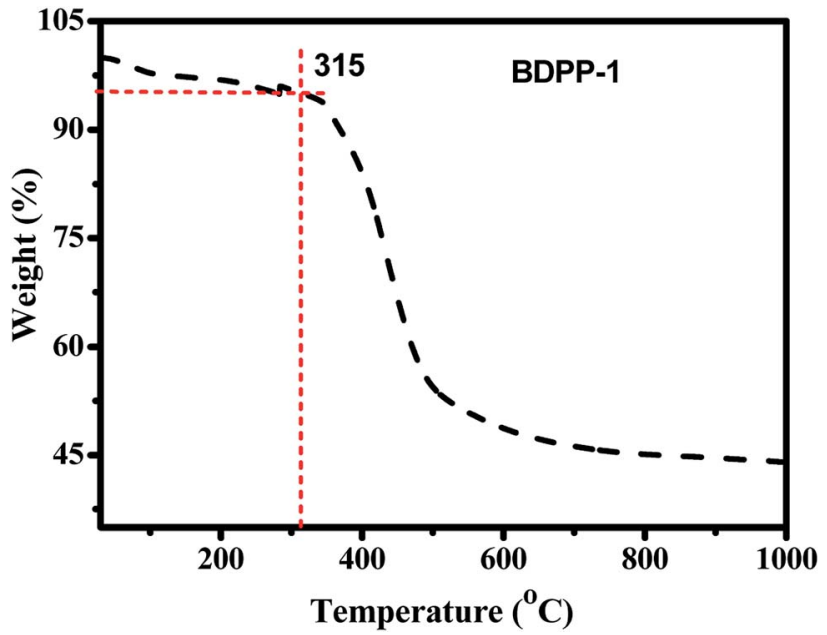

Fig. 2 TGA plot of BDPP-1 recorded at a heating rate of $10{ }^{\circ} \mathrm{C} \mathrm{min}-1$ under a nitrogen atmosphere.

the solid state. Moreover, the shoulder absorption peak around $567 \mathrm{~nm}$ was clearly observed from the thin-film, which further indicated the stronger $\pi$-stacking due to the crystalline nature of the small molecule. ${ }^{44,45}$ The optical band gap $\left(E_{\mathrm{g}}^{\mathrm{opt}}\right)$ was calculated from the absorption edge of the BDPP-1 film to be $1.65 \mathrm{eV}$, which is an ideal range for OPV applications. ${ }^{43}$

Optical spectral red shifts in the absorption and fluorescence are expected in polar solvents because of the stabilization of the ICT occurring between the terminal donor-acceptor groups. To prove the hypothesis, the absorption and the fluorescence spectra of the star-shaped molecule BDPP-1 $(1.0 \times$ $10^{-5} \mathrm{~mol} \mathrm{~L}^{-1}$ ) were investigated in eight organic solvents with different polarities such as $\mathrm{CCl}_{4}$, toluene, $\mathrm{CH}_{2} \mathrm{Cl}_{2}$, ether, $\mathrm{CHCl}_{3}$, ethylacetate, THF and acetone due to varying polarities. ${ }^{\mathbf{4 6}}$ Firstly, the absorption property of the compound BDPP-1 was characterized in different organic solvents (Fig. 4). A slightly positive solvatochromism is clearly observed, as the absorption

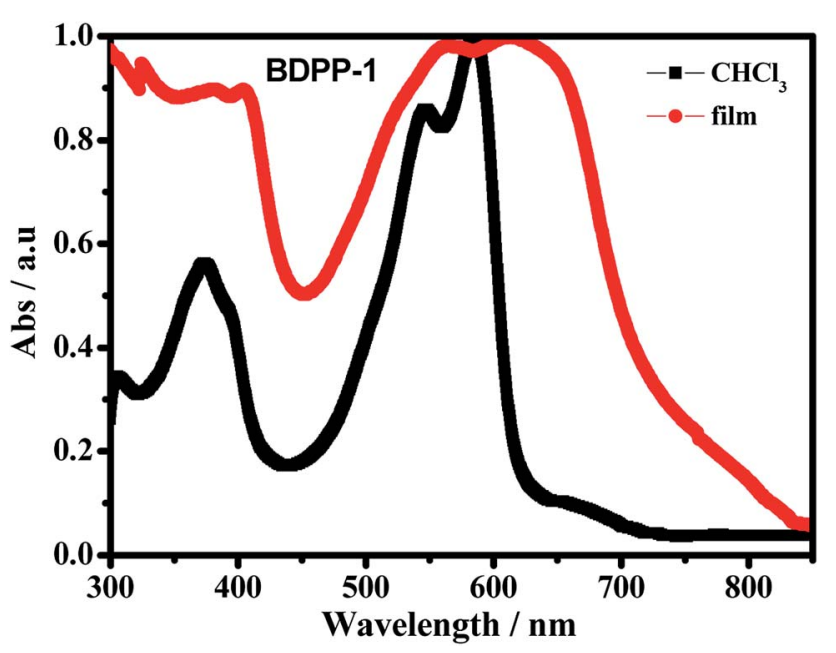

Fig. 3 Normalized UV-vis absorption spectra of BDPP-1 in chloroform and in thin film. 


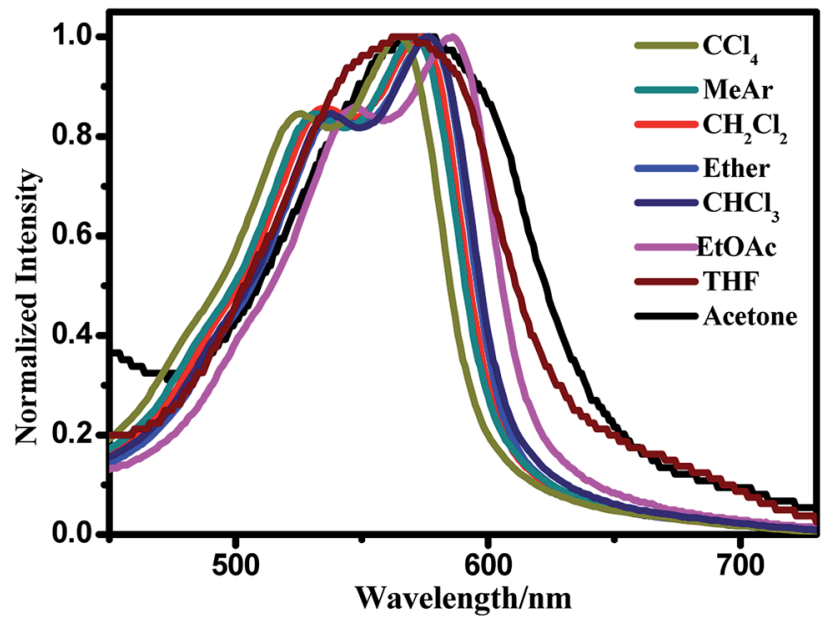

Fig. 4 Normalized absorption spectra of BDPP-1 $\left(1.0 \times 10^{-5} \mathrm{M}\right)$ in different solvents.

maxima in polar solvents is red shift compared to that in apolar solvents (Table 1). This observation indicates that the electronic excitation increases the dipole moment of the molecules and that the directions of the ground and excited state dipoles are similar to each other. ${ }^{47}$ That's to say, the electron transition types do not change and the red shift is caused by ICT process, which has been significantly affected by the surrounding medium. ${ }^{48}$

Subsequently, the fluorescence spectra of the compound BDPP-1 were studied in eight solvents with different polarities. As shown in Fig. 5, the fluorescence emission peaks were redshifted obviously with increasing solvent polarity, and the emission maxima is $620 \mathrm{~nm}$ in $\mathrm{CCl}_{4}$ and $656 \mathrm{~nm}$ in acetone. As BDPP-1 contains an electron donorgroup and an acceptor group, a charge transfer (CT) probably happen in the excited state from the electron-donor moiety to the electron-acceptor moiety. And the CT process is expected to greatly increase the dipole moment in the excited state, therefore, which can explain the positive fluorescence solvatochromism in the compound BDPP-1. The shape of the fluorescence spectra bears a slight change, indicating that the change of solvent polarity plays an impact on the emissive center. Meanwhile, no new emission peak occurs, suggesting that the significant ICT process remains in different solvents. And the change in full width half maximum (FWHM, becoming wider) confirms that the emissive

Table 1 Spectroscopic properties of BDPP-1 in different solvents

\begin{tabular}{llll}
\hline Solvent & $\lambda_{\text {abs }}$ & $\lambda_{\mathrm{FL}}$ & Stokes shift \\
\hline $\mathrm{CCl}_{4}$ & 569 & 620 & 51 \\
$\mathrm{MeAr}$ & 571 & 624 & 53 \\
$\mathrm{CH}_{2} \mathrm{Cl}_{2}$ & 571 & 636 & 65 \\
Ether & 577 & 638 & 61 \\
$\mathrm{CHCl}_{3}$ & 577 & 640 & 63 \\
EtOAc & 581 & 645 & 64 \\
THF & 585 & 650 & 65 \\
Acetone & 583 & 656 & 73
\end{tabular}

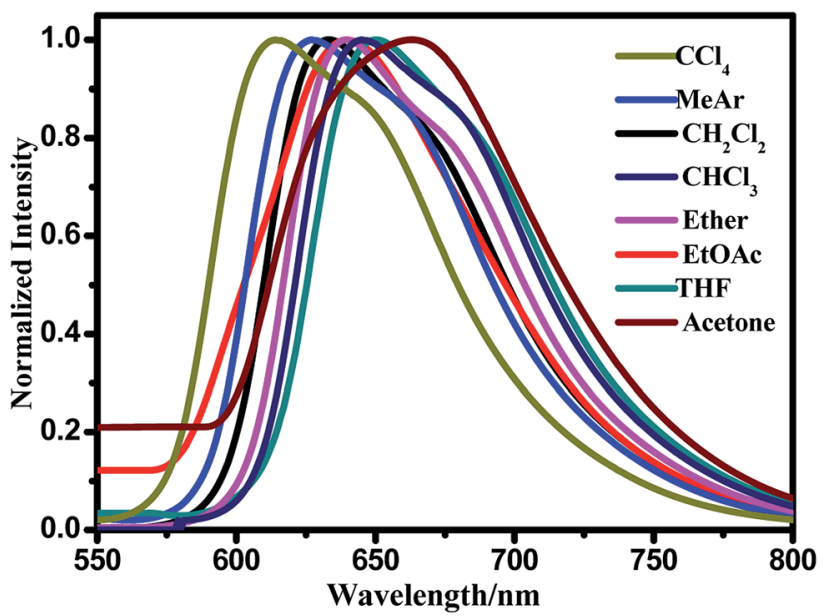

Fig. 5 Normalized fluorescence spectra of BDPP-1 $\left(1.0 \times 10^{-5} \mathrm{M}\right)$ in different solvents.

center is stabilized by polar solvent molecules and the excitation state could be stabilized, thus resulting in the wider spectra. However, at the same condition, the absorption is almost no affected, suggests that a typical ICT effect happens after excitation, prior to emission, and that the emission stems from a strongly dipolar emissive state. The stabilization of the ICT state by solvent molecules (the so-called solvent relaxation), leads to great changes in the emission intensity and shape of emission bands. Generally, the more the solvent polarizes the lower energy of the relaxed state and the larger red-shift in fluorescence spectra can be clearly observed. ${ }^{49}$ This relaxation effect is the essential for the polarity-dependent fluorescence of the compound BDPP-1.

In addition, the solvent-dependent spectral shift is generally interpreted by the orientation polarizability $(\Delta f)$, according to the Lippert-Mataga method. ${ }^{50}$ This involves plotting the observed Stokes shift $(\Delta v)$ as a function of the solvent's orientation polarizability $(\Delta f)$, which is described by solvent's refractive index $(n)$ and its dielectric constant $(\varepsilon)$, according to the Lippert-Mataga equation: $\Delta f=(\varepsilon-1 / 2 \varepsilon+1)-\left(n^{2}-1 / 2 n^{2}+\right.$ 1). As clearly seen from Fig. 6 , a fine linear correlation between the Stokes shift of BDPP-1 and the solvent orientation polarizability was found, indicating the involvement of solvent polarity dependent ICT emissive states.

\section{Photoinduced charge-separation properties}

To evaluate the photoinduced charge separation process between donor and acceptor, the fluorescence quenching experiment was performed with the synthesized donor material BDPP-1 and PC $_{61}$ BM, as shown in Fig. 7. As expected, the fluorescence quenching phenomenon of BDPP-1 was clearly revealed. The fluorescence intensity of BDPP-1 gradually decreased with the increasing concentration of $\mathrm{PC}_{61} \mathrm{BM}$, indicating an efficient charge separation process between the synthesized donor and acceptor $\mathrm{PC}_{61} \mathrm{BM}$. Moreover, the dependence of fluorescence intensity on the concentration of quencher $\mathrm{PC}_{61} \mathrm{BM}$ is well linear at low concentrations in 


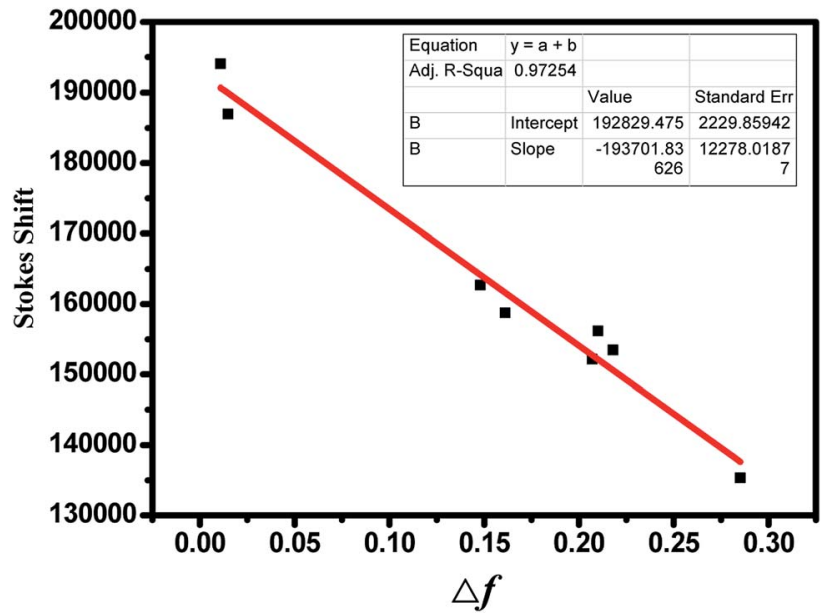

Fig. 6 Dependence of the Stokes shifts of compound BDPP-1 as a function of the Lippert parameter $(\Delta f)$.

(a)

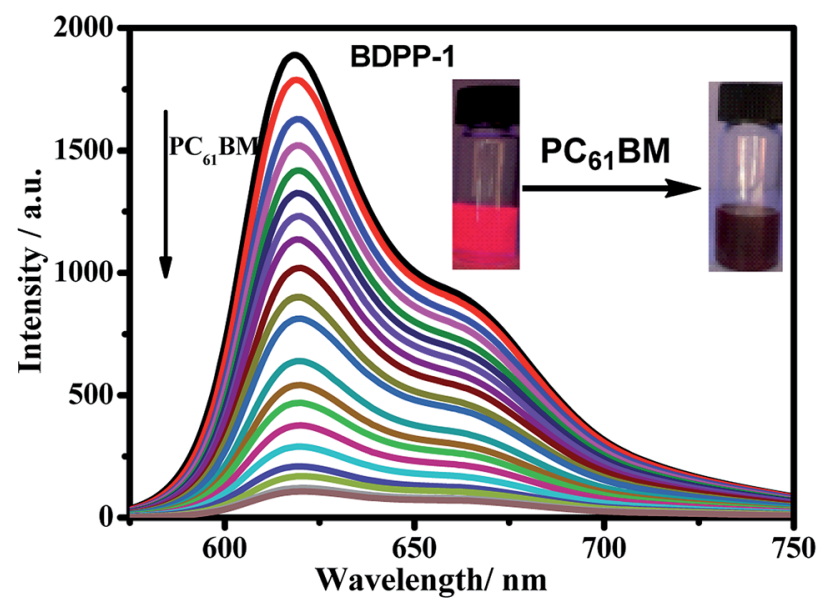

(b)

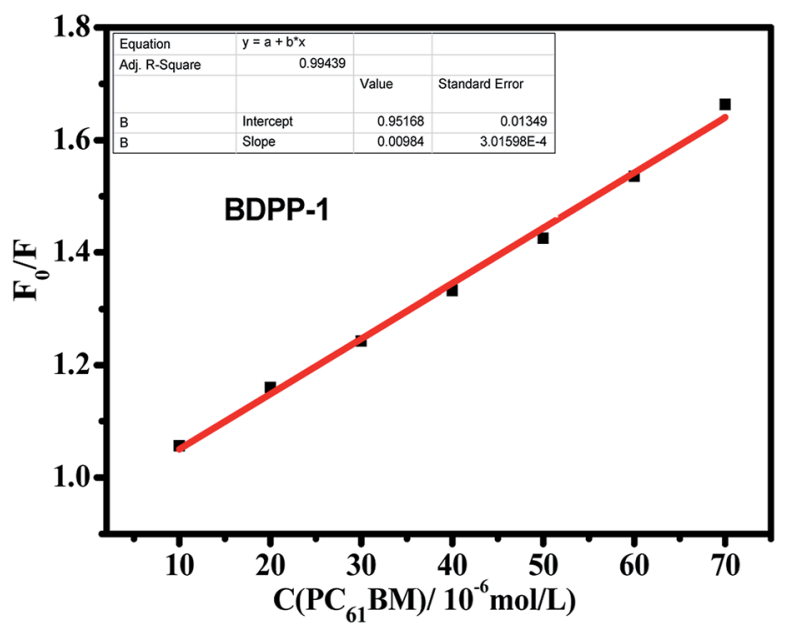

Fig. 7 (a) Emission spectra of BDPP-1 $\left(1.0 \times 10^{-5} \mathrm{M}\right)$ in $\mathrm{CHCl}_{3}$ with increasing concentration of $\mathrm{PC}_{61} \mathrm{BM}(0-10$ equiv.); inset: fluorescence of BDPP-1 without and with $\mathrm{PC}_{61} \mathrm{BM}$ in $\mathrm{CHCl}_{3}$ under UV light $(365 \mathrm{~nm})$; (b) Stern-Volmer quenching fitting plot for BDPP-1. conformity with the Stern-Volmer equation: ${ }^{51} F_{0} / F=1+K_{\mathrm{SV}}[\mathrm{C}]$, where $F_{0}$ and $F$ represent the emission intensity in the absence and presence of $\mathrm{PC}_{61} \mathrm{BM}$, respectively, $K_{\mathrm{SV}}$ is the fluorescence quenching constant, and $[\mathrm{C}]$ is the concentration of $\mathrm{PC}_{61} \mathrm{BM}$. According to Stern-Volmer equation, the fitting plot of the BDPP-1 is shown in Fig. 7b. Accordingly, the $K_{\mathrm{SV}}$ value of BDPP-1 is $1.8 \times 10^{4} \mathrm{M}^{-1}$. The high $K_{\mathrm{SV}}$ value showed that the material presents the efficient charge separation process. Among the solar cell materials, $\mathbf{P 3} \mathbf{H T}$ and $\mathbf{P C}_{\mathbf{6 1}} \mathbf{B M}$ are classical donor and acceptor materials. Compared with donor material P3HT, ${ }^{52}$ our designed small molecule BDPP-1 shows obvious advantages such as the higher value of $K_{\mathrm{SV}}$, providing the more efficient charge separation process, as well as the broader absorption band in the solution and film state (Table 2). Thus, the synthesized star-shaped small molecule BDPP-1 is the good candidate for the donor material in the OPV field.

\section{Electrochemical properties ${ }^{+}$}

To further evaluate the potential applicability in electronic devices, the electrochemical properties and energy levels of the star-shaped small molecule BDPP-1 were studied by cyclic voltammetry (CV) experiment. As shown in Fig. 8, the first onset oxidation potential was observed at $0.89 \mathrm{~V}$, which was also confirmed by the differential pulse voltammetry (DPV) result (Fig. S5 $\dagger$ ), whereas the onset reduction potential at $-0.75 \mathrm{~V}$. The electrochemical band gap $\left(E_{\mathrm{g}}^{\mathrm{CV}}\right)$ and the corresponding energy levels $\left(\mathrm{HOMO}^{\mathrm{CV}}\right.$ and $\mathrm{LUMO}^{\mathrm{CV}}$ ) could be achieved from $E_{\mathrm{Ox}}$ and $E_{\text {red }}$ by using the following empirical equations: $:^{53} E_{\mathrm{HOMO}}{ }^{\mathrm{cv}}=$ $-\left(E_{\mathrm{ox}}-E_{1 / 2}^{\mathrm{Fc}}+5.1\right) \mathrm{eV}$ and $E_{\mathrm{LUMO}} \mathrm{cv}^{\mathrm{cv}}=-\left(E_{\mathrm{red}}-E_{1 / 2}^{\mathrm{Fc}}+5.1\right) \mathrm{eV}$, where $E_{\mathrm{ox}}$ and $E_{\mathrm{red}}$ are the measured onset potentials relative to $\mathrm{Ag} / \mathrm{Ag}^{+} . E_{1 / 2}^{\mathrm{Fc}}=0.05 \mathrm{~V}$ versus $\mathrm{Ag} / \mathrm{Ag}^{+}$. Consequently, the $\mathrm{HOMO}^{\mathrm{CV}}$ and LUMO $^{\mathrm{CV}}$ levels for BDPP-1 are -5.94 and $-4.30 \mathrm{eV}$, respectively. The result indicates that BDPP-1 has a relatively deep HOMO energy level, implied that it has good stability in the air. Because of the relatively low HOMO energy level, BDPP-1 maybe has potential application in organic photoelectric and photovoltaic materials. ${ }^{54}$ The electrochemical band gap $\left(E_{\mathrm{g}}^{\mathrm{CV}}\right)$ of BDPP-1 estimated from the CV measurement was $1.64 \mathrm{eV}$, which was consistent with its optical band gap $\left(E_{\mathrm{g}}^{\text {opt }}\right)$ of $1.65 \mathrm{eV}$. Based on these above investigated results, the $\mathrm{CV}$ experimental data are very important to explain their optical-electronic properties and provide an important guide for better understanding the relationship between the star-shaped molecular structure and property.

\section{Theoretical calculations}

In order to gain more detailed insight into the electronic characteristics including the molecular energy levels and electronic density distributions of the presented target compound BDPP-1,

Table 2 Photophysical properties of P3HT and BDPP-1

\begin{tabular}{|c|c|c|c|c|}
\hline Compound & $\lambda_{\mathrm{abs}}^{\max }(\mathrm{nm})$ & & $\lambda_{\mathrm{em}}^{\max }(\mathrm{nm})$ & $K_{\mathrm{SV}}\left(\mathrm{M}^{-1}\right)$ \\
\hline P3HT & $452\left(\mathrm{CHCl}_{3}\right)$ & 545 (film) & $573\left(\mathrm{CHCl}_{3}\right)$ & $2.4 \times 10^{3}$ \\
\hline BDPP-1 & $577\left(\mathrm{CHCl}_{3}\right)$ & 614 (film) & $640\left(\mathrm{CHCl}_{3}\right)$ & $1.8 \times 10^{4}$ \\
\hline
\end{tabular}




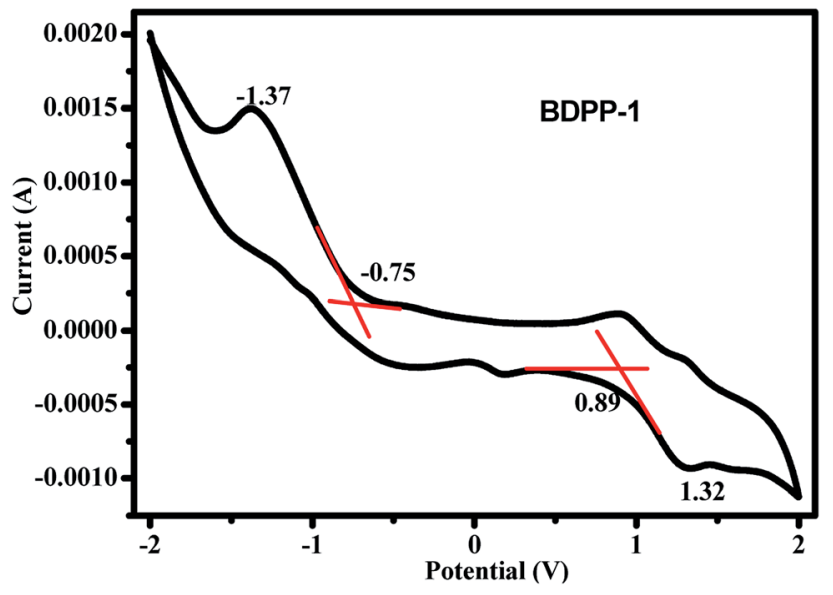

Fig. 8 Cyclic voltammogram of BDPP-1 in $0.1 \mathrm{M} \mathrm{LiClO}_{4}$ solution under $\mathrm{N}_{2}$ at a scanrate of $100 \mathrm{mV} \mathrm{s}^{-1}$.

density functional theory (DFT) calculations with Gaussian 03 software at the B3LYP/6-311G (d,p) level ${ }^{55}$ have been performed as shown in Fig. S6. $\dagger$ For DFT calculations, the alkyl chains in the molecule BDPP-1 were replaced by methyl groups. As shown in Fig. S6a, $\uparrow$ the geometric structure optimized by DFT theoretical calculation indicate that the star-shaped molecule exhibits a rigid spatial structure and has a good planar structure. Seen from the Fig. S6b, $\uparrow$ the electronic densities of HOMO are mainly distributed the central donor core and two terminal DPP groups, whereas those of LUMO are predominantly located on the two terminal DPP groups, revealing an effective ICT transition from the electron-donating segment to the electronwithdrawing unit. The introduction of $\pi$-bridge $(-\mathrm{C} \equiv \mathrm{C}-)$ has an positive effect on their charge transfer properties. The calculated energy levels of the $\mathrm{HOMO}^{\mathrm{DFT}}$ and $\mathrm{LUMO}^{\mathrm{DFT}}$ are $-5.51 \mathrm{eV}$ and $-3.77 \mathrm{eV}$, respectively, and the calculated band gap is $1.74 \mathrm{eV}$. The error of the calculated to the experimental values anyway adjudges within the $0.3 \mathrm{eV}$ margin that is typical of DFT calculations. ${ }^{\mathbf{5 6 , 5 7}}$ These findings are in very good agreement with the experimentally recorded HOMO/LUMO energies. These DFT results could provide important reference for the experimental data and preliminarily guide for the strategy of molecular design.

\section{Conclusions}

In this work, we have successfully designed and synthesized a novel star-shaped small molecule BDPP-1 based on 1,3,5triethynylbenzene as a core and alkyl-DPP as rigid arms. The synthesized star-shaped small molecule BDPP-1 exhibited excellent solubility in common organic solvents, high thermal stability (over $315{ }^{\circ} \mathrm{C}$ ), broad absorption range $(300-760 \mathrm{~nm}$ ), high molar extinction coefficient $\left(>10^{5} \mathrm{M}^{-1} \mathrm{~cm}^{-1}\right)$, narrow band gap (below $2.0 \mathrm{eV}$ ), and the efficient photoinduced charge separation performance. These excellent thermal, optical, electrochemical properties and photoinduced charge separation performance show especial promise as a new donor material for potential applications in small molecule organic solar cells.

\section{Conflicts of interest}

There are no conflicts to declare.

\section{Acknowledgements}

We are thankful for the financial support from the National Natural Science Foundation of China (No. 21376125 and 21776143), the Natural Science Foundation of Shandong Province (No. ZR2017LB009), the program for College Students' Innovation and Entrepreneurship Training of Shandong Province (No. S201910431035), the Program for Scientific Research and the Program for Scientific Research Innovation Team in Colleges and Universities of Shandong Province (No. 0308150302).

\section{Notes and references}

1 Z. Li, Q. Dong, Y. Li, B. Xu, M. Deng, J. Zhang, F. Chen, S. Wen, Y. Gao and W. Tian, J. Mater. Chem., 2011, 21, 2159-2168.

2 D. Sahu, C. Tsai, H. Wei, K. Ho, F. Chang and C. Chu, J. Mater. Chem., 2012, 22, 7945-7953.

3 A. Leliège, C. Régent, M. Allain, P. Blanchard and J. Roncali, Chem. Commun., 2012, 48, 8907-8909.

4 Y. Kim, C. Song, A. Cho, J. Kim, Y. Eom, J. Ahn, S. Moon and E. Lim, Mater. Chem. Phys., 2014, 143, 825-829.

5 Q. Fan, M. Li, P. Yang, Y. Liu, M. Xiao, X. Wang, H. Tan, Y. Wang, R. Yang and W. Zhu, Dyes Pigm., 2015, 116, 13-19.

6 J. Peter, B. Jean and H. Yves, Adv. Mater., 2012, 25, 19481954.

7 K. Lim, S. Lee, K. Song, G. Sharma and J. Ko, J. Mater. Chem. C, 2014, 2, 8412-8422.

8 F. Liang, F. Shi, Y. Fu, L. Wang, X. Zhang, Z. Xie and Z. Su, Sol. Energy Mater. Sol. Cells, 2010, 94, 1803-1808.

9 M. Fischer, Q. Ma, R. Janssen, T. Debaerdemaeker and P. Bauerle, J. Mater. Chem., 2009, 19, 4784-4795.

10 Z. Jiang, T. Ye, C. Yang, D. Yang, M. Zhu, C. Zhong, J. Qin and D. Ma, Chem. Mater., 2011, 23, 771-777.

11 Y. Zhang, L. Chen, K. Zhang, H. Wang and Y. Xiao, Chem.Eur. J., 2014, 20, 10170-10178.

12 T. Figueira-Duarte and K. Mullen, Chem. Rev., 2011, 111, 7260-7314.

13 Y. Lin, Y. Li and X. Zhan, Chem. Soc. Rev., 2012, 41, 42454272.

14 M. Amaresh and B. Peter, Angew. Chem., Int. Ed., 2012, 51, 2020-2067.

15 Y. Lin, Y. Wang, J. Wang, J. Hou, Y. Li, D. Zhu and X. Zhan, Adv. Mater., 2014, 26, 5137-5142.

16 L. Schmidt-Mende, A. Fechtenkotter, K. Mullen, E. Moons, R. Friend and J. MacKenzie, Science, 2001, 293, 1119-1122.

17 Y. Zhang, D. Hanifi, S. Alvarez, F. Antonio, A. Pun, L. Klivansky, A. Hexemer, B. Ma and Y. Liu, Org. Lett., 2011, 13, 6528-6531. 
18 J. Min, Y. Luponosov, A. Gerl, M. Polinskaya, S. Peregudova, P. Dmitryakov, A. Bakirov, M. Shcherbina, S. Chvalun, S. Grigorian, N. Kaush-Busies, S. Ponomarenko, T. Ameri and C. Brabec, Adv. Energy Mater., 2014, 4, 1301234.

19 H. Shang, H. Fan, Y. Liu, W. Hu, Y. Li and X. Zhan, Adv. Mater., 2011, 23, 1554-1557.

20 S. Paek, N. Cho, S. Cho, J. Lee and J. Ko, Org. Lett., 2012, 14, 6326-6329.

21 J. Min, Y. Luponosov, A. Solodukhin, N. Kausch-Busies, S. Ponomarenko, T. Ameri and C. Brabec, J. Mater. Chem. C, 2014, 2, 7614-7620.

22 S. Diring, F. Puntoriero, F. Nastasi, S. Campagna and R. Ziessel, J. Am. Chem. Soc., 2009, 131, 6108-6110.

23 D. Frantz, J. Walish and T. Swager, Org. Lett., 2013, 15, 47824785.

24 M. Chen, W. Fu, M. Shi, X. Hu, J. Pan and J. Ling, J. Mater. Chem. A, 2013, 1, 105-111.

25 Y. Lin, L. Ma, Y. Li, Y. Liu, D. Zhu and X. Zhan, Adv. Energy Mater., 2013, 3, 1166-1170.

26 D. Yu, Y. Liu, M. Xiao, Q. Fan, W. Su, X. Li, H. Tan, Y. Wang, R. Yang and W. Zhu, Dyes Pigm., 2015, 10, 6.

27 S. Zhang, T. Sun, Z. Xu, T. Li, Y. Li, Q. Niu and H. Liu, Tetrahedron Lett., 2017, 58, 2779-2783.

28 S. Zhang, Q. Niu, T. Sun, Y. Li, T. Li and H. Liu, Spectrochim. Acta, Part A, 2017, 183, 172-176.

29 R. Zhou, Q. Li, X. Li, X. Lu, L. Wang and C. Zhang, Dyes Pigm., 2014, 101, 51-57.

30 S. Li, W. Liu, M. Shi, J. Mai, T. Lau, J. Wan, X. Lu, C. Li and H. Chen, Energy Environ. Sci., 2016, 9, 604-610.

31 C. Wang, C. Mueller, E. Gann, A. Liu, M. Thelakkat and C. McNeill, J. Mater. Chem. A, 2016, 4, 3477-3486.

32 R. Ashraf, I. Meager, M. Nikolka, M. Kirkus, M. Planells, B. Schroeder, S. Holliday, M. Hurhangee, C. Nielsen, H. Sirringhaus and I. McCulloch, J. Am. Chem. Soc., 2015, 137, 1314-1321.

33 M. Kaur and D. Choi, Chem. Soc. Rev., 2015, 44, 58-77.

34 J. Pei, J. Wang, X. Cao, X. Zhou and W. Zhang, J. Am. Chem. Soc., 2003, 125, 9944-9945.

35 A. Kanibolotsky, R. Berridge, P. Skabara, I. Perepichka, D. Bradley and M. Koeberg, J. Am. Chem. Soc., 2004, 126, 13695-13702.

36 S. Sergeyev, W. Pisula and Y. H. Geerts, Chem. Soc. Rev., 2007, 36, 1902-1929.
37 A. C. Grimsdale, K. L. Chan, R. E. Martin, P. G. Jokisz and A. B. Holmes, Chem. Rev., 2009, 109, 897-1091.

38 J. Luo, Y. Zhou, Z.-Q. Niu, Q.-F. Zhou, Y. Ma and J. Pei, J. Am. Chem. Soc., 2007, 129, 11314-11315.

39 X. Zhang, J. Lu and J. Zhang, Chem. Mater., 2014, 26, 40234029.

40 Q. Niu, Y. Lu, H. Sun and X. Li, Spectrochim. Acta, Part A, 2013, 107, 377-385.

41 S. Loser, C. Bruns, H. Miyauchi, R. Ortiz, A. Facchetti, S. Stupp and T. Marks, J. Am. Chem. Soc., 2011, 133, 81428145.

42 M. Tsai, Y. Hsu, J. Lin, H. Chen and C. Hsu, J. Phys. Chem. C, 2007, 111, 18785-18793.

43 G. He, X. Wan, Z. Li, Q. Zhang, G. Long, Y. Liu, Y. Hou, M. Zhang and Y. Chen, J. Mater. Chem. C, 2014, 2, 1337-1345.

44 M. Turbiez, P. Frere, M. Allain, C. Videlot, J. Ackermann and J. Roncali, Chem.-Eur. J., 2005, 11, 3742-3752.

45 C. Uhrich, R. Schueppel, A. Petrich, M. Pfeiffer, K. Leo, E. Brier, P. Kilickiran and P. Baeuerle, Adv. Funct. Mater., 2007, 17, 2991-2999.

46 A. Bolduc, Y. Dong, A. Guérinz and W. G. Skene, Phys. Chem. Chem. Phys., 2012, 14, 946-956.

47 O. A. Kucherak, L. Richert, Y. Mély and A. S. Klymchenko, Phys. Chem. Chem. Phys., 2012, 14, 2292-2300.

48 R. S. Moog, D. D. Kim, J. J. Oberle and S. G. Ostrowski, J. Phys. Chem. A, 2004, 108, 9294-9301.

49 Y. Yang, B. Li and L. Zhang, Sens. Actuators, B, 2013, 183, 4651.

50 J. L. M. Abboud and R. Notario, Pure Appl. Chem., 1999, 71, 645-718.

51 T. Zhao, Z. Liu, Y. Song, W. Xu, D. Zhang and D. Zhu, J. Org. Chem., 2006, 71, 7422-7432.

52 J. M. Lobez, T. L. Andrew, V. Bulović and T. M. Swager, ACS Nano, 2012, 6, 3044-3056.

53 G. Gritzner and J. Kuta, Pure Appl. Chem., 1984, 56, 461-466.

54 S. Wen, J. Pei, Y. Zhou, P. Li, L. Xue, Y. Li, B. Xu and W. Tian, Macromolecules, 2009, 42, 4977-4984.

55 M. J. Frisch, et al., Gaussian 03, Gaussian Inc, Wallingford CT, 2004.

56 D. Jacquemin, V. Wathelet, E. Perpète and C. Adamo, J. Chem. Theory Comput., 2009, 5, 2420-2435.

57 D. Jacquemin, E. Perpète, I. Ciofini and C. Adamo, Theor. Chem. Acc., 2010, 128, 127-136. 